\title{
Bivalent Carbamates as Novel Control Agents of the Malaria Mosquito, Anopheles gambiae
}

\author{
James M. Mutungaae, Qiao-Hong Chen ${ }^{b}$, Dawn M. Wong ${ }^{b}$, Polo C-H. Lam ${ }^{d}$, Jianyong Lic, \\ Maxim M. Totrov' ${ }^{\mathrm{d}}$, Aaron D. Gross ${ }^{\mathrm{a}}$, Paul R. Carlier ${ }^{\mathrm{b}}$, and Jeffrey R. Bloomquist ${ }^{\mathrm{a}}$
}

\begin{abstract}
Widespread pyrethroid resistance has caused an urgent need to develop new insecticides for control of the malaria mosquito, Anopheles gambiae. Insecticide discovery efforts were directed towards the construction of bivalent inhibitors that occupy both the peripheral and catalytic sites of the mosquito acetylcholinesterase (AChE). It was hypothesized that this approach would yield a selective, high potency inhibitor that would also circumvent known catalytic site mutations (e.g. G119S) causing target site resistance. Accordingly, a series of bivalent phthalimide-pyrazole carbamates were prepared having an alkyl chain linker of varying length, along with other modifications. The most active compound was (1-(3-(1,3-dioxoisoindolin-2-yl)propyl)-1H-pyrazol-4-yl methylcarbamate, $\mathbf{8 a}$ ), which has a chain length of three carbons, good mosquito anticholinesterase activity, and ca. 5-fold selectivity compared to human AChE. Moreover, this compound was toxic to mosquitoes by topical application $\left(\mathrm{LD}_{50}=63 \mathrm{ng} / \mathrm{female}\right.$ ) with only 6-fold cross resistance in the Akron strain of Anopheles gambiae that showed 50- to 60-fold resistance to conventional carbamate insecticides. However, contact lethality in the WHO paper assay was disappointing. The implications of these results for design of new mosquitocides are discussed.
\end{abstract}

Keywords: Anticholinesterase $\cdot$ Catalytic site $\cdot$ Molecular docking $\cdot$ Peripheral site

\section{Introduction}

Chemical use of insecticides for mosquito control has remained an important tool and component for the integrated vector management of malaria and other vector-borne diseases. The Roll Back Malaria Abuja declaration in the year $2000^{[1]}$ set forth an ambitious plan to reduce mortality and morbidity due to malaria in Africa through an array of ways and means, among them use of insecticide treated nets (ITNs) and indoor residual spraying (IRS). Since then, success in reducing malaria mortality and morbidity due to expansive ITN use has been widely documented. ${ }^{[2-4]}$ Although IRS has been widely used, especially in malaria endemic

${ }^{\star}$ Correspondence: Dr. J. R. Bloomquist ${ }^{2}$ E-mail: jbquist@epi.ufl.edu

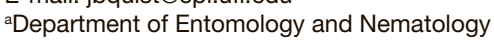
Emerging Pathogens Institute

University of Florida, Gainesville, FL 32610, USA

'Department of Chemistry, Virginia Tech

Blacksburg, VA 24061, USA

'Department of Biochemistry, Virginia Tech

Blacksburg, VA 24061, USA

'Molsoft LLC

11199 Sorrento Valley Road

San Diego, CA 92121, USA

${ }^{\circ}$ Current address: Human Health Division

International Centre of Insect Physiology and Ecology (ICIPE)

P.O. Box 30772-00100, Nairobi, Kenya. areas, some reports show that ITNs provide superior protection against malaria. ${ }^{[5]}$ A combination of both IRS and ITNs has been shown to provide enhanced protection against malaria. ${ }^{[6,7]}$

Pyrethroids are the only insecticides currently approved by WHO for deployment with ITNs and continued use has led to the emergence of resistance. ${ }^{[8]}$ Current reports indicate that insecticide resistance in malaria vectors is increasing all over Africa, ${ }^{[9]}$ hence the need for urgent measures to mitigate possible control failure. In semi-field studies, the use of carbamate-treated nets has shown good efficacy in controlling mosquitoes, even in pyrethroid-resistant populations. ${ }^{[10-12]}$ However, current commercial carbamates are not effective for control of ace-1 resistantmosquitoes, which express a modified acetylcholinesterase possessing a G119S mutation. ${ }^{[13,14]}$ Conventional carbamates can also have appreciable side effects in exposed humans, ${ }^{[11]}$ thereby limiting their use. There is a need to develop new insecticides that are less toxic to humans and effective on resistant mosquitoes to be used as alternatives in mixtures and/or rotations with pyrethroids.

One proposed strategy to achieve this goal is to design bivalent inhibitors of cholinesterases that are able to bind simultaneously and selectively to the peripheral and catalytic sites of AChE. This approach has been attempted in insects through compounds that bind to the catalytic site atttached to another tethered ligand that binds to the peripheral site ${ }^{[15-18]}$ or that bears a chemically reactive group targeting thiols. ${ }^{[15,19,20]}$ Using this approach, selective and covalent inhibition of AChE was demonstrated. Bivalent organophosphorus ${ }^{[21]}$ and carbamate ${ }^{[17,18]}$ inhibitors were shown in some cases to be potent inhibitors of Drosophila melanogaster and Musca domestica AChE, and have moderate toxicity to Tetranychus cinnbarinus and Lipaphis erysimi. The present study was undertaken to explore further the potential of bivalent carbamate AChE inhibitors to provide selective, resistance-breaking insecticides for malaria vector control.

\section{Materials and Methods}

\subsection{Insects}

An. gambiae strains G3 (a reference susceptible strain) and Akron (insecticide-resistant) were obtained from BEI Resources, through the CDC-MR4. Akron mosquitoes have both knockdown resistance $(k d r)$ to pyrethroids (L1014F) and the G119S mutation $\left(\right.$ ace $\left.-1^{\mathrm{R}}\right)$, which confers resistance to carbamates, in addition to elevated levels of carboxylesterase and cytochrome P450 monooxygenase activities. ${ }^{[22]}$ Mosquito colonies were maintained at the Fralin Life Science Center insectary (Virginia Tech) or reared from eggs at the Emerging Pathogens Institute, University of Florida), 
under $75 \%$ relative humidity and $28^{\circ} \mathrm{C}$, with a 12:12 dark:light cycle. Treated mosquitoes were held in environmental chambers maintained under similar conditions.

\subsection{Chemicals and Solvents}

Propoxur (technical grade), ethanol, piperonyl butoxide (PBO), and Ellman reagents were purchased from SigmaAldrich Chemical Co. (St. Louis, MO, USA). Terbam was synthesized according to published procedures.[23] Phthalimidetethered bivalent carbamates were synthesized as shown in Scheme 1. In brief, pyrazole (1) was converted to 4-iodopyrazole (2), and phthalimide was reacted with $\alpha, \omega$-dibromoalkanes to afford phthalimide-tethered $1^{\circ}$ alkyl bromides 4a-d. $N$-alkylation of $\mathbf{2}$ with $\mathbf{4 a - d}$ afforded 5a-d. Palladium-catalyzed borylation afforded $\mathbf{6 a}-\mathbf{d}$, and oxidative deborylation afforded pyrazol-4-yl-ols 7a-d. Reaction with methylcarbamoyl chloride afforded a mixture of the anticipated methylcarbamates 8a-d, and the rarely seen allophanates $9 \mathbf{a}-\mathbf{d}$. Careful chromatographic separation afforded pure samples of each. To assess the effect of $\mathrm{N}, \mathrm{N}$-disubstitution on the reactivity and toxicity of the bivalent carbamates, 7a was treated with dimethylcarbamoyl chloride to afford 10a. All compounds were characterized by ${ }^{1} \mathrm{H}$ and ${ }^{13} \mathrm{C}$ NMR, and HRMS and were purified to $>$ 95\% before enzyme and mosquito toxicity assays.

\subsection{Mosquito Toxicity Assays}

All bioassays were run on 2-5 day old An. gambiae, non-blood fed females. A WHO-type protocol, slightly modified, ${ }^{[23,24]}$ was used to assess paper contact toxicity. Solutions of each compound (up to $1 \mathrm{mg} / \mathrm{mL}$ ) were applied to a $12 \mathrm{~cm} \times$ $15 \mathrm{~cm}$ paper, with $95 \%$ ethanol as solvent, which was allowed to evaporate. Mosquitoes were anesthetized on ice, and acclimatized for $1 \mathrm{~h}$ in a WHO cylindrical holding chamber. Mosquitoes were then moved to the treatment chamber lined with treated paper and left for $1 \mathrm{~h}$, after which they were placed in paper cups and provided with $10 \%$ sugar solution ad libitum for $24 \mathrm{~h}$. Topical treatments utilized $200 \mathrm{~nL}$ of chemical solution (dissolved in 95\% ethanol) applied to the insect pronotum using a handheld Hamilton ${ }^{\circledR}$ microapplicator. Synergism studies with PBO were performed as a topical $4 \mathrm{~h}$ pretreatment (100 ng) before topical application of carbamate. For injection, $100 \mathrm{~nL}$ was introduced into the thorax in insect saline containing insecticide dissolved in ethanol (no more than $5 \%$ ethanol final concentration).[25] After treatments, mosquitoes were held for $24 \mathrm{~h}$ as described above. A solventonly treatment was included in each experiment as a negative control, and $24 \mathrm{~h}$ mortality data were analyzed by log-probit using Poloplus ${ }^{\circledR}$ (LeOra software Co. CA, USA) to generate the $24 \mathrm{~h} \mathrm{LC}_{50}$ or $\mathrm{LD}_{50}$ of each chemical, the concentration or dose

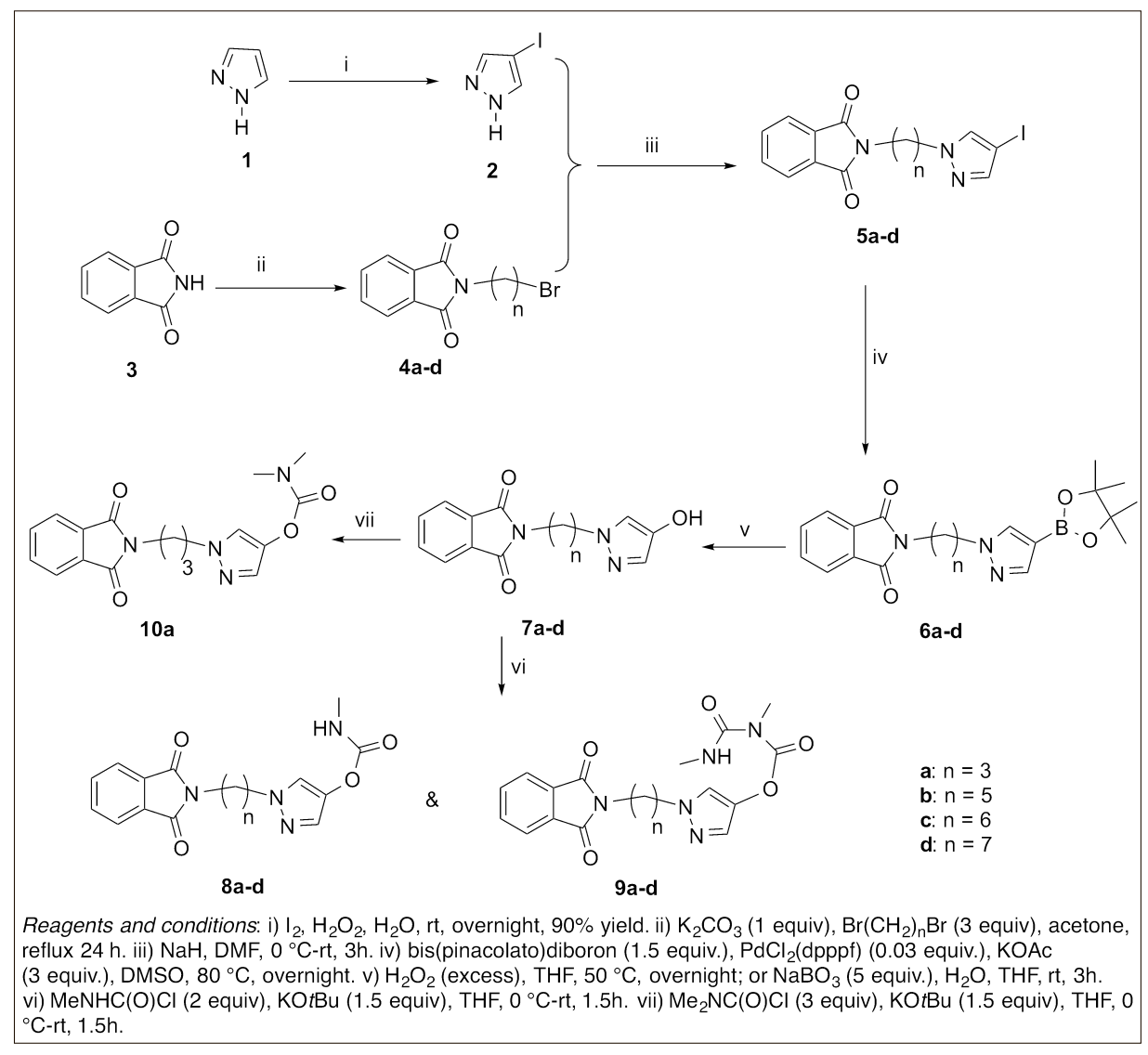

Scheme 1. Synthesis of pyrazol-4-yl bivalent carbamates. at which $50 \%$ of treated mosquitoes were dead.

\subsection{AChE Inhibition Assays}

Enzyme was prepared from homogenates of frozen Anopheles gambiae $(A g \mathrm{AChE})$ as described in previous studies. ${ }^{[15,24]}$ Recombinant human $\mathrm{AChE}$ $(h \mathrm{AChE})$ was purchased from SigmaAldrich and recombinant constructs of the catalytic subunit of wild type (LiN) and its cognate resistant mutant (G119S) were prepared as described in a prior publication. ${ }^{[24]} \mathrm{AChE}$ activity was measured using the Ellman method adapted for a 96-well microplate assay on a 96-well plate reader (Dynex, Chantilly, VA, USA), with inhibition rate constants for each inhibitor and compound determined as described previously. ${ }^{[24]}$

\subsection{Molecular Modeling}

Inhibitor molecule was docked into a homology model of $A g \mathrm{AChE}$, constructed as reported by Carlier et al. ${ }^{[15]}$ All in silico modeling steps were performed in Molsoft ICM software (Molsoft, San Diego, CA USA), as described previously. ${ }^{[26,27]}$

\section{Results and Discussion}

Chemical synthetic efforts (Scheme 1) were directed towards the assembly of structurally novel bivalent inhibitors that might occupy both the peripheral and catalytic sites on the mosquito enzyme. These compounds utilized a pyrazole as the central moiety, because its smaller size relative to the phenyl ring was shown previously to alleviate the high cross-resistance values found among typical carbamate insecticides. ${ }^{[24]}$ The pyrazoles were tethered to a phthalimido group via alkyl tethers of varying length $(\mathbf{8 a}-\mathbf{d})$, along with matched tether length allophanate analogs $(\mathbf{9 a}-\mathbf{d})$ and a single $N, N$-dimethyl carbamate (10a). Initial screening for contact insecticidal activity was by WHO paper assay to adult female mosquitoes. All the bivalents showed low and variable contact toxicity to mosquitoes in this assay, regardless of changes in tether length, or derivatization to allophanate and $\mathrm{N}, \mathrm{N}$-dimethyl analogs (Table 1). This activity stands in contrast to the performance of propoxur and terbam in this same paper assay, where both compounds showed $\mathrm{LC}_{50}$ values of 39 and 37 $\mu \mathrm{g} / \mathrm{mL}$, respectively. [24]

Hypothesizing that the variable toxicity observed for these compounds might be due to poor transfer from filter paper, topical application studies were undertaken of compounds 8a-d (Table 2). While compounds $\mathbf{8 b}-\mathbf{d}$ were inactive, $\mathbf{8 a}$ had significant toxicity by this route of exposure, but was 14-fold and 20-fold less active than the 
Table 1. Toxicity of pyrazol-4-yl/phthalimide bivalent compounds ( $\mathrm{n}=$ the number of methylene groups in the linker) observed at $24 \mathrm{~h}$ when susceptible G3 mosquitoes were exposed to $1 \mathrm{mg} / \mathrm{mL}$ in the WHO paper assay.

\begin{tabular}{|l|l|r|}
\hline Compound & $\mathrm{n}$ & Toxicity \\
\hline 8a & 3 & $c a .16 \%$ \\
\hline 9a & 3 & $c a .12 \%$ \\
\hline $\mathbf{1 0 a}$ & 3 & $c a .28 \%$ \\
\hline $\mathbf{8 b}$ & 5 & $c a .20 \%$ \\
\hline 9b & 5 & $0 \%$ \\
\hline $\mathbf{8 c}$ & 6 & $0 \%$ \\
\hline 9c & 6 & $0 \%$ \\
\hline 8d & 7 & $10 \%$ \\
\hline 9d & 7 & $10 \%$ \\
\hline
\end{tabular}

established carbamates terbam and propoxur, respectively. Similarly, 10a showed topical lethality to An. gambiae females, albeit 2.7-fold less than 8a. Topical assays with $8 \mathbf{a}$ on resistant Akron mosquitoes also gave encouraging results. Only mild resistance was observed in Akron when treated with $\mathbf{8 a}$, in contrast to much greater levels of resistance observed for propoxur and terbam (Table 2). Interestingly, 8a, terbam, and propoxur are roughly equitoxic to G3 An. gambiae by injection (Table 2). Toxicity is increased 13-fold and 15-fold for propoxur and terbam, respectively, following injection, while for $\mathbf{8 a}$, the effect is more pronounced (263-fold), suggesting that cuticular penetration is an important factor impacting its insecticidal activity. The extent to which penetration could be enhanced by different adjuvant formulations of $\mathbf{8 a}$ remains to be investigated. Finally, piperonyl butoxide, a monooxy-

Table 2. Topical and injection toxicity studies of bivalent $N$-methylcarbamates, compared to established carbamate insecticides, propoxur and terbam.

\begin{tabular}{|c|c|c|c|c|c|}
\hline Compound & $\mathrm{n}$ & $\begin{array}{l}\text { G3 Topical } \\
{ }^{\mathrm{a}} \mathrm{LD}_{50}\end{array}$ & $\begin{array}{l}\text { Akron Topical } \\
{ }^{\mathrm{a}} \mathrm{LD}_{50}\end{array}$ & ${ }^{b} \mathrm{RR}$ & $\begin{array}{l}\text { G3 Injection } \\
{ }^{a} \mathrm{LD}_{50},\end{array}$ \\
\hline $\mathbf{8 a}$ & 3 & $63(55-72)$ & $386(340-430)$ & 6 & $0.24(0.16-0.30)$ \\
\hline $10 \mathbf{a}$ & 3 & $168(118-205)$ & - & - & - \\
\hline $8 b$ & 5 & 0\%@200ng & - & - & - \\
\hline $8 c$ & 6 & 0\%@200ng & - & - & - \\
\hline 8d & 7 & 0\%@200ng & - & - & - \\
\hline propoxur & & c3.2(2.4-4.2) & d201 (138-295) & 63 & $0.24(0.17-0.34)$ \\
\hline terbam & & c4.5 (3.6-5.4) & d223 (202-245) & 50 & $0.30(0.17-0.50)$ \\
\hline
\end{tabular}

${ }^{a} \mathrm{LD}_{50}$ in $\mathrm{ng} /$ female or \% mortality at the indicated concentration; 95\% confidence limits in

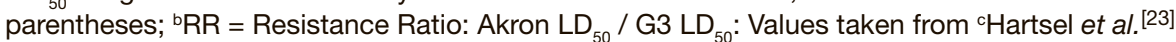
and dMutunga et al.[22]

genase-inhibiting synergist ${ }^{[28]}$ was tested with $\mathbf{8 a}$ and 10a (Fig. 1) to ascertain the impact of oxidative metabolism on toxicity. These studies demonstrated a significant increase in toxicity for $\mathbf{8 a}$ following $4 \mathrm{~h}$ pretreatment with $\mathrm{PBO}(\mathrm{P}=0.015)$, with a slight decrease $(\mathrm{P}=0.17)$ in the toxicity of 10a (Fig. 1). The findings suggest that metabolism is playing a limited role in the toxicity of these compounds.

Enzyme inhibition studies were performed on selected compounds to assess the intrinsic potency of the bivalent carbamates at the target site (Table 3 ) and compare their inhibitory activities to those of propoxur and terbam. Comparing responses on G3 homogenate, it was observed that $\mathbf{8 a}$ is a more potent inhibitor than $\mathbf{8 b}$ and

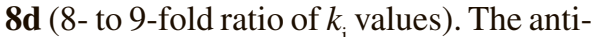
cholinesterase action of $\mathbf{9 b}$ was much less, while propoxur had about one third the activity of 8a and terbam approached a 2-fold

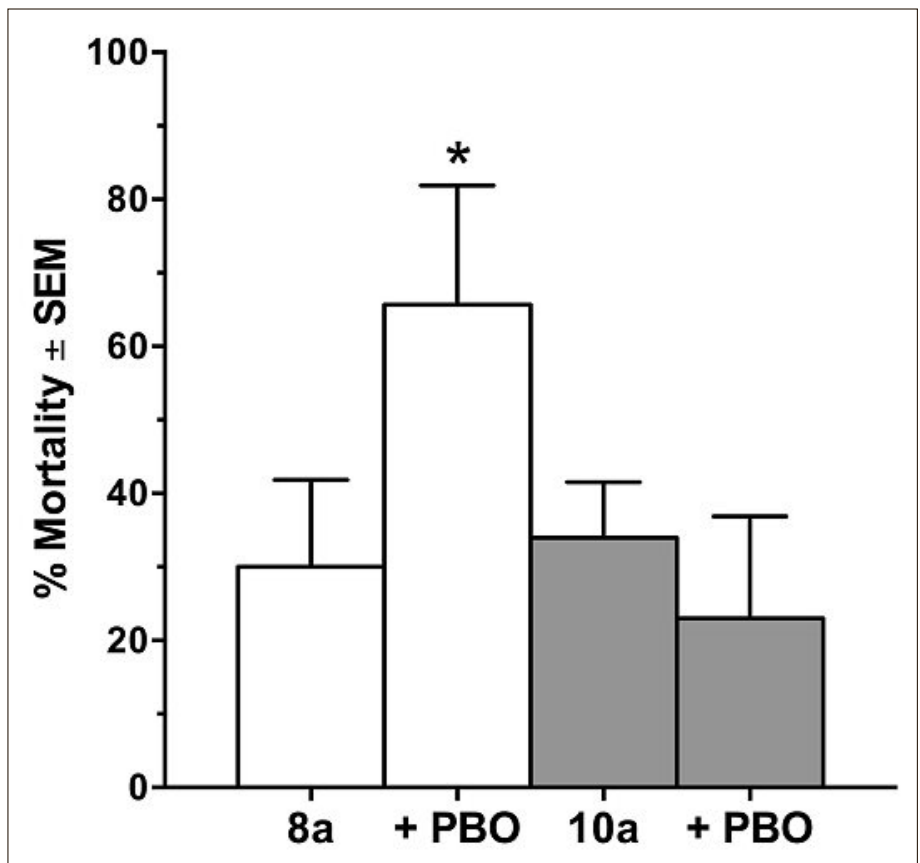

greater activity than $\mathbf{8 a}$. In terms of $h \mathrm{AChE}$ selectivity ratios, $8 \mathbf{a}>\mathbf{8 b}=\mathbf{8 d}>\mathbf{9 d}$ (Table 3). Compared to $\mathbf{8} \mathbf{a}$, terbam and propoxur had 2.6-fold and 3.6-fold, respectively greater selectivity for mosquito enzyme compared to human. There were variable levels of resistance observed to bivalent carbamates by the Akron (homogenate) and engineered G119S enzymes, but in all cases was much lower than that expressed against propoxur and terbam.

The intrinsic potency of the bivalent carbamates at the target site, as assessed using mosquito homogenates as enzyme sources, was also compared with results for recombinant enzymes (Table 3). We reported previously on both recombinant Anopheles gambiae AChE and its G119S mutant, and verified that the recombinant wild type and resistant enzymes behaved identically in their sensitivity to conventional aryl-substituted carbamates as the native enzymes from G3 and Akron homogenates, respectively. ${ }^{[24]}$ The present data indicate that inhibitory constants of bivalent carbamates were also essentially the same for both susceptible and resistant mosquito homogenates and recombinant enzymes, with the same rank order of potencies, resistance ratios, and selectivity ratios (Table 3 ). These results suggest that the catalytic mechanism and gorge geometry do not differ significantly between homogenates and recombinant enzymes.

Molecular modeling studies suggest that compound $\mathbf{8 a}$ probably interacts with both the catalytic and peripheral site on $A g A C h E$, as intended (Fig. 2). In the catalytic site, carbamate interacts with the oxyanion hole, forming hydrogen bonds to backbone $\mathrm{N}-\mathrm{H}$ groups of residues $\mathrm{G} 118$ and A200. These interactions position carbamate for the nucleophilic attack on S199 hydroxyl, and the pyrazole nitrogen forms a hydrogen bond to Y121 sidechain. The phthalimido moiety is mostly occupying 
Table 3. Enzyme inhibition constants of pyrazol-4-yl/phthalimide bivalents on mosquito strain homogenates (hmg), recombinant mosquito AChE constructs (bold), and human AChE.

\begin{tabular}{|c|c|c|c|c|}
\hline Cmpd & $\begin{array}{c}\text { a Susceptible } k_{i} \text { : } \\
\text { G3 hmg } \\
\text { LiN }\end{array}$ & $\begin{array}{c}\text { a Resistant } k_{i} \text { : } \\
\text { Akron hmg } \\
\text { G119S }\end{array}$ & ${ }^{\mathrm{b}} \mathrm{RR}$ & ${ }^{\mathrm{a}} h \mathrm{AChE}$ \\
\hline $8 \mathbf{a}$ & $\begin{array}{l}951 \pm 39 \\
831 \pm \mathbf{2 4}\end{array}$ & $\begin{array}{c}16.8 \pm 0.7 \\
6.5 \pm \mathbf{0 . 5}\end{array}$ & $\begin{array}{c}57 \\
128\end{array}$ & $174 \pm 7$ \\
\hline $8 b$ & $\begin{array}{l}109 \pm 2 \\
\mathbf{1 0 5} \pm \mathbf{1}\end{array}$ & $\begin{array}{l}7.0 \pm 0.5 \\
\mathbf{5 . 3} \pm \mathbf{0 . 1}\end{array}$ & $\begin{array}{l}16 \\
20\end{array}$ & $91.5 \pm 4.2$ \\
\hline $9 \mathrm{~b}$ & $\begin{array}{l}0.15 \pm 0.02 \\
\mathbf{0 . 1 6} \pm \mathbf{0 . 0 2}\end{array}$ & $\begin{array}{l}0.05 \pm 0.02 \\
\mathbf{0 . 0 8} \pm \mathbf{0 . 0 2}\end{array}$ & $\begin{array}{l}3 \\
2\end{array}$ & $0.16 \pm 0.04$ \\
\hline $8 d$ & $\begin{array}{c}101 \pm 3 \\
108 \pm 13\end{array}$ & $\begin{array}{l}4.7 \pm 0.4 \\
\mathbf{4 . 9} \pm \mathbf{0 . 2}\end{array}$ & $\begin{array}{l}21 \\
22\end{array}$ & $87.5 \pm 3.7$ \\
\hline${ }^{\mathrm{d}}$ propoxur & $\begin{array}{l}323 \pm 8 \\
266 \pm 9\end{array}$ & $\begin{array}{l}0.040 \pm 0.005 \\
\mathbf{0 . 0 3 7} \pm \mathbf{0 . 0 0 7}\end{array}$ & $\begin{array}{l}8075 \\
\mathbf{7 1 8 9}\end{array}$ & $17.0 \pm 0.4$ \\
\hline${ }^{d}$ terbam & $\begin{array}{c}1710 \pm 20 \\
1510 \pm \mathbf{1 0 0}\end{array}$ & $\begin{array}{c}0.65 \pm 0.06 \\
\mathbf{0 . 4} \pm \mathbf{0 . 0 3}\end{array}$ & $\begin{array}{l}2630 \\
\mathbf{3 7 7 5}\end{array}$ & $126 \pm 3$ \\
\hline
\end{tabular}

${ }^{\mathrm{a}} \mathrm{k}_{i}$ values $\left(\mathrm{mM}^{-1} \mathrm{~min}^{-1}\right) \pm \mathrm{SEM}$ determined according to the method of Hartsel et al.[23]; ${ }^{\mathrm{b} R R}=$ Resistance Ratio: G3 hmg $k_{i}$ / Akron hmg $k_{i}$ or LiN $k_{i} /$ G119S $k_{i}$; 'SR = Selectivity Ratio: G3 AChE $k_{i} / h$ AChE $k_{i}$ or LiN $k_{i} / h$ AChE $k_{i}$; dData for propoxur and terbam taken from Wong et al.[24]

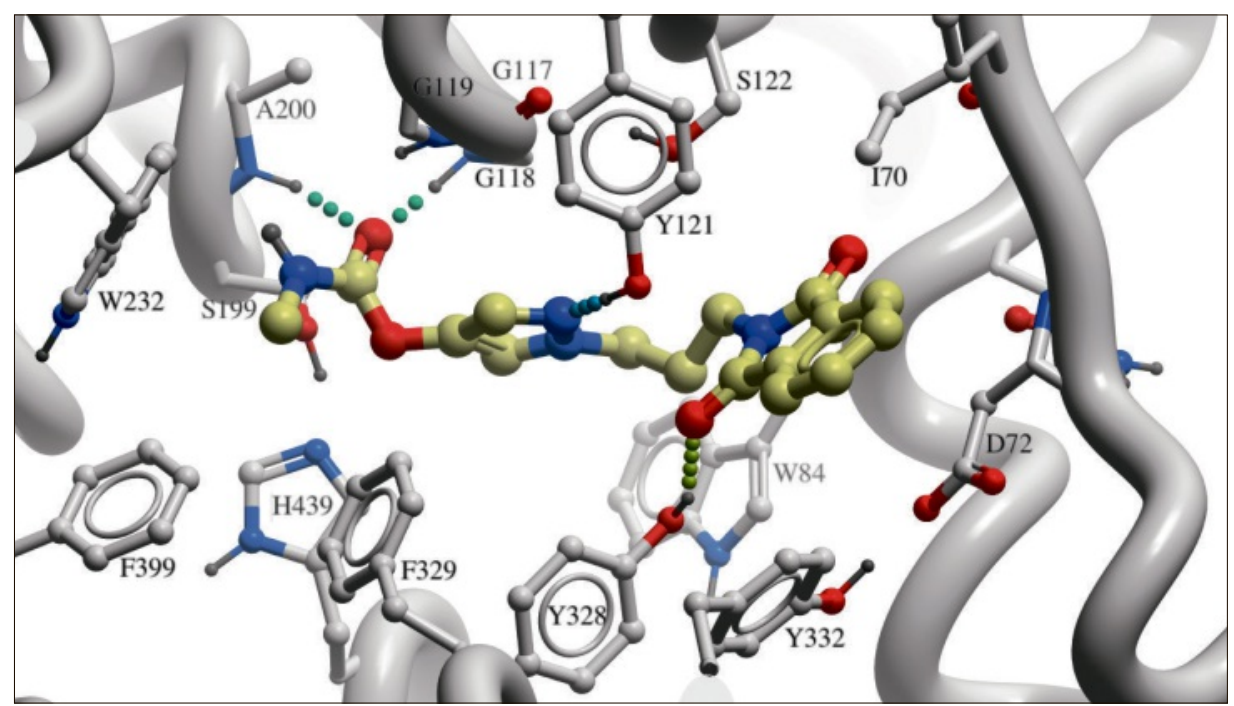

Fig. 2. Molecular homology model of $\mathbf{8 a}$ docked into the catalytic site and gorge of susceptible AChE. See text for explanation.

the 'gorge' that connects peripheral and catalytic sites, making a hydrogen bond to Y328 and contacts with Y121 and Y332 side-chains as well as V71 and D72 backbone. It does not reach as far as the key W280 peripheral site side-chain, which was observed to interact extensively with the corresponding moiety in the X-ray structure of the galanthamine-phthalimide bivalent inhibitor complex (PDB ID 1W4L). ${ }^{[29]}$ This novel interaction mode is in agreement with the much shorter linker in our inhibitor, $-\left(\mathrm{CH}_{2}\right)_{3}-$ as compared to $-\left(\mathrm{CH}_{2}\right)_{8}$ - in the previously reported bivalent compound. [29]

A partial correspondence was observed between in vitro AChE inhibition and in vivo toxicity. The rank order of potency for bivalent carbamates against susceptible $A g \mathrm{AChE}$ is reflected in their toxicity to whole mosquitoes. In particular, the in vitro high activity of $\mathbf{8 a}$ is consistent with its potent injected toxicity, although its topical activity is significantly less than propoxur and terbam. Given the lower, but significant anticholinesterase activity of $\mathbf{8 b}$ and 8d (about one third that of propoxur), topical doses above $200 \mathrm{ng}$ would be expected to produce mortality. There is somewhat of a disconnect, however, for comparisons involving the G119S enzyme and in vivo toxicity. We observed a 6-fold difference in toxicity, but a 55- to 128-fold difference in enzyme sensitivity for $\mathbf{8 a}$ (Tables 2 and 3). A similar difference was observed for propoxur and terbam, where in vitro inhibitory activity differed by several thousand fold, but resistance ratios in vivo were 50-63 crepancy remain unclear at present. (Tables 2 and 3 ). The reasons for this dis-
The phthalimide moiety has been used previously to affect binding of inhibitors to the peripheral site of AChE. For example, several phthalimide heterodimers were prepared and based upon their enzyme inhibition potencies, molecular modeling studies suggested that they interacted with both the catalytic and peripheral sites of Torpedo californica AChE. ${ }^{[30]}$ In addition, a series of $N$-methyl ${ }^{[16]} N, N$-dimethyl[17] carbamate phenyl-phthalimide heterodimers (tethers of $\mathrm{C}_{3}-\mathrm{C}_{10}$ ) were synthesized and assayed for inhibition potency against M. domestica AChE. The most potent compound in each series was connected to the phthalimido group via a three-carbon tether, with $\mathrm{IC}_{50}$ values in the low micromolar range. Little insect toxicity data were reported for these compounds, and no shorter tethers were synthesized. Of the bivalent carbamates reported here, a three-carbon tether was optimal for both anticholinesterase activity and lethality, but analogs having two and four carbons should be evaluated.

\section{Conclusions}

Compound 8a is the first bivalent anticholinesterase that can potently inhibit $A n$. gambiae $\mathrm{AChE}$ and cause demonstrated lethality to both susceptible and carbamate- and pyrethroid-resistant mosquitoes. The smaller core structure of pyrazol-4-yl relative to a phenyl ring is in large part responsible for the ability to link a large ligand without abrogating AChE inhibitory potency, and the lack of basic nitrogen groups allows for permeation of the bloodbrain barrier, as well as facilitating contact insecticidal activity. Based upon these observations, it should be possible to design additional bivalent carbamate inhibitors with improved contact toxicity, low cross resistance, and target site selectivity.

\section{Acknowledgments}

We thank Paul Howell of the MR4 as part of the BEI Resources Repository, NIAID, $\mathrm{NIH}$, for providing eggs of the G3 (MRA-112) and Akron (MRA-913) strains of Anopheles gambiae. We also thank the FNIH, Grand Challenges in Global Health (\#1497, to J.R.B.), the Innovative Vector Control Consortium (to P.R.C), and USDA Hatch Project (FLAENY-005237, to J.R.B.) for financial support.

Received: July 20, 2016

[1] WHO, 2003, http://www.who.int/malaria/ publications/atoz/whocdsrbm200346/en/ accessed June 24, 2016.

[2] P. A. Howard, B. L. Nahlen, M. S. Kolczak, A. W. Hightower, F. O. ter Kuile, J. A. Alaii, J. Gimnig, J. Arudo, J. M. Vulule, A. Odhacha, S. P. Kachur, E. Schoute, D. H. Rosen, J. D. Sexton, A. J. Oloo, W. A. Hawley, Am. J. Trop. Med. Hyg. 2003, 68, 23. 
[3] R. W. Steketee, N. Sipilanyambe, J. Chimumbwa, J. J. Banda, A. Mohamed, J. Miller, S. Basu , S. K. Miti, C. C. Campbell, Am. J. Trop. Med. Hyg. 2006, 79, 45.

[4] F. O. ter Kuile, D. J. Terlouw, P. A. PhillipsHoward, W. A. Hawley, J. F. Friedman, S. K. Kariuki, Y. P. Shi, M. S. Kolczak, A. A. Lal, J. M. Vulule, B. L. Nahlen, Am. J. Trop. Med. Hyg. 2003, 68, 50 .

[5] B. Pluess, F. C. Tanser, C. Lengeler, B. L. Sharp, Cochrane Database Syst. Rev. 2010, 4, CD006657.

[6] J. E. Gimnig, P. Otieno, V. Were, D. Marwanga, D. Abong'o, R. Wiegand, J. Williamson, A. Wolkon, Y. Zhou, M. N. Bayoh, N. F. Lobo, K. Laserson, S. Kariuki, M. J. Hamel, PLoS ONE 2016, 11, e0145282.

[7] N. Protopopoff, A. Wright, P. A. West, R. Tigererwa, F. W. Mosha, W. Kisinza, I. Kleinschmidt, M. Rowland, PLoS ONE 2015, 10, e0142671.

[8] H. Ranson, R. N'Guessan, J. Lines, N. Moiroux, Z. Nkuni, V. Corbel, Trend. Parasitol. 2011, 27 , 91

[9] H. Ranson, N. Lissenden, Trends Parasitol. 2016, 32, 187

[10] C. Fanello, J. H. Kolaczinski, D. J. Conway, P. Carnevale, C. F. Curtis, Parassitologia 1999, 41, 323.

[11] P. Guillet, R. N'Guessan, F. Darriet, M. TraoreLamizana, F. Chandre, P. Carnevale, Med. Vet. Entomol. 2000, 15, 105.
[12] M. Rowland, R. N'Guessan, ACS Symp. Ser. 2009, 1014, 13 .

[13] R. N'guessan, F. Darriet, P. Guillet, P. Carnevale, M. Traore-Lamizana, V. Corbel, A. A. Koffi, F. Chandre, Med. Vet. Entomol. 2003, 17,1 .

[14] M. Weill, C. Malcolm, F. Chandre, K. Mogensen, A. Berthomieu, M. Marquine, M. Raymond, Insect Mol. Biol. 2004, 13, 1.

[15] P. R. Carlier, T. D. Anderson, D. M. Wong, D. C. Hsu, J. Hartsel, M. Ma, E. A. Wong, R. Choudhury, P. C. H. Lam, M. M. Totrov, J. R. Bloomquist, Chem.-Biol. Inter. 2008, 175, 368.

[16] Q. F. Zhao, G. Q. Yang, X. D. Mei, J. Ning, J. Pestic. Sci. $2008,33,371$.

[17] Q. F. Zhao, G. Q. Yang, X. D. Mei, J. Ning, Pestic. Biochem. Physiol. 2009, 95, 131.

[18] H. J. Ma, R. L Xie, Q. F. Zhao, X. D. Mei, J. Ning, J. Agric. Food Chem. 2010, 58, 12817.

[19] Y.-P. Pang, S. K. Singh, Y. Gao, T. L. Lassiter, R. K. Mishra, K. Y. Zhu, S. Brimijoin, PLoS ONE 2009, 4, e6851.

[20] D. Dou, J. G. Park, S. Rana, B. J. Madden, H. Jiang, Y.-P. Pang, Sci. Rep. 2013, 3, 1068.

[21] R. Xie, Q. Zhao, T. Zhang, J. Fang, X. Mei, J. Ning J, Y. Tang, Bioorg. Med. Chem. 2013, 21, 278

[22] J. M. Mutunga, T. D. Anderson, D. T. Craft, A. D. Gross, D. R. Swale, F. Tong, D. M. Wong, P. R. Carlier, J. R. Bloomquist, Pestic. Biochem. Physiol. 2015, 121, 116
[23] J. A. Hartsel, D. M. Wong, J. M. Mutunga, M. Ma, T. D. Anderson, A. Wysinski, R. Islam, E. A. Wong, S. L. Paulson, J. Li, P. C.-H. Lam, M. Totrov, J. R. Bloomquist, P. R. Carlier, Bioorg. Med. Chem. Lett. 2012, 22, 4593.

[24] D. M. Wong, J. Li, Q.-H. Chen, Q. Han, J. Mutunga, A. Wysinski, T. Anderson, H. Ding, T. Carpenetti, A. Verma, R. Islam, S. Paulson, P. Lam, M. Totrov, J. Bloomquist, P. Carlier, PLoS ONE 2012, 7, e46712.

[25] E. Camerino, D. M. Wong, F. Tong, F. Körber, A. D. Gross, R. Islam, E. Viayna, J. M Mutunga, J. Li, M. M. Totrov, J. R. Bloomquist, P. R. Carlier, Biorg. Med. Chem. Lett. 2015, 25, 4405.

[26] M. Totrov, R. Abagyan, Proteins 1997, Suppl 1, 215.

[27] V. Katritch, M. Rueda, R. Abagyan, Methods Mol Biol. 2012, 857, 189.

[28] S.J. Yu, 'The Toxicology and Biochemistry of Insecticides', Taylor \& Francis, 2008.

[29] H. M. Greenblatt, C. Guillou, D. Guénard, A. Argaman, S. Botti, B. Badet, C. Thal, I. Silman, J. L. Sussman, J. Am. Chem. Soc. 2004, 126, 15405.

[30] Y. Yamamoto, Y. Ishihara, I. D. Kuntz, J. Med. Chem. 1994, 37, 3141. 